\title{
Lead-halide perovskites meet donor-acceptor charge-transfer complexes
}

Supporting Information

Nadège Marchal*,1, Wouter Van Gompel ${ }^{2}$, María C. Gélvez-Rueda ${ }^{3}$, Koen Vandewal $^{5}$, Kristof Van Hecke ${ }^{4}$, Hans-Gerd Boyen ${ }^{5}$, Bert Conings ${ }^{5}$, Roald Herckens $^{2}$, Sudeep Maheshwari ${ }^{3}$, Laurence Lutsen ${ }^{6}$, Claudio Quarti ${ }^{1}$, Ferdinand C. Grozema ${ }^{3}$, Dirk Vanderzande ${ }^{2}$, David Beljonne ${ }^{1}$

\footnotetext{
${ }^{1}$ Laboratory for Chemistry of Novel Materials, University of Mons, Place du Parc, 20, B7000 Mons, Belgium

${ }^{2}$ Hasselt University, Institute for Materials Research (IMO-IMOMEC), Hybrid Materials Design (HyMaD), Martelarenlaan 42, B-3500 Hasselt, Belgium

${ }^{3}$ Optoelectronic Materials Section, Department of Chemical Engineering, Delft University of Technology, Van der Maasweg 9, 2629 HZ Delft, The Netherlands

${ }^{4}$ Ghent University, Department of Chemistry, XStruct, Krijgslaan 281-S3, B-9000 Ghent, Belgium

${ }^{5}$ Hasselt University, Institute for Materials Research, (IMO-IMOMEC) Wetenschapspark 1, 3590 Diepenbeek, Belgium

${ }^{6}$ IMEC, Associated Laboratory IMOMEC, Wetenschapspark 1, B-3590 Diepenbeek, Belgium
} 


\section{TABLE OF CONTENTS}

S3 Experimental details of the single crystal XRD measurement

S4 Supporting figures and tables

S4 Powder XRD

S5 Comparison between 2D and 1D hybrids containing CTCs

S6 Scanning probe microscopy

S7 Absorption Spectra

S8 Theoretical methodological study

S9 Bader analysis

S9 Partial Density of States

S10 Pulse-Radiolysis TRMC

S11 Photoconductivity TRMC

S14 Thermal stability of the hybrid

S15 References 


\section{Experimental details of the single crystal XRD measurement}

For the structure of $\left(\mathbf{P y r C}_{4} \mathbf{N H}_{3}\right) \mathbf{P b I}_{3}{ }^{\bullet}(\mathbf{T C N Q})$, X-ray intensity data were collected at $100 \mathrm{~K}$ on a Rigaku Oxford Diffraction Supernova Dual Source ( $\mathrm{Cu}$ at zero) diffractometer equipped with an Atlas CCD detector using $\omega$ scans and $\operatorname{CuK} \alpha(\lambda=0.71073 \AA)$ radiation. The images were interpreted and integrated with the program CrysAlisPro ${ }^{1}$. Using Olex $2^{2}$, the structure was solved by direct methods using the ShelXS structure solution program and refined by full-matrix least-squares on $\mathrm{F}^{2}$ using the ShelXL program package ${ }^{3,4}$. Non-hydrogen atoms were anisotropically refined and the hydrogen atoms in the riding mode and isotropic temperature factors fixed at 1.2 times $\mathrm{U}(\mathrm{eq})$ of the parent atoms.

Crystal data for compound (PyrC $\left.\boldsymbol{N}_{4} \mathbf{N H}_{3}\right) \boldsymbol{P b I}_{3} \bullet(\boldsymbol{T C N Q}) . \mathrm{C}_{32} \mathrm{H}_{24} \mathrm{I}_{3} \mathrm{~N}_{5} \mathrm{~Pb}, M=1066.46$, monoclinic, space group Ia (No. 9), $a=8.0302(2) \AA, b=42.3950(9) \AA, c=9.4390(2) \AA, \beta=97.458(2)^{\circ}, V=3186.23(13)$ $\AA^{3}, Z=4, T=100 \mathrm{~K}, \rho_{\text {calc }}=2.223 \mathrm{~cm}^{-3}, \mu(\mathrm{Cu}-\mathrm{K \alpha} \alpha)=8.232 \mathrm{~mm}^{-1}, F(000)=1968,46480$ reflections measured, 8105 unique $\left(R_{\text {int }}=0.0523\right)$ which were used in all calculations. The final $R 1$ was 0.0260 ( $I$ $>2 \sigma(I))$ and $w R 2$ was 0.0556 (all data).

CCDC 1899647 contains the supplementary crystallographic data for this paper and can be obtained free of charge via www.ccdc.cam.ac.uk/conts/retrieving.html (or from the Cambridge Crystallographic Data Centre, 12, Union Road, Cambridge CB2 1EZ, UK; fax: +44-1223-336033; or deposit@,ccdc.cam.ac.uk). 


\section{Supporting figures and tables}

\section{Powder XRD}

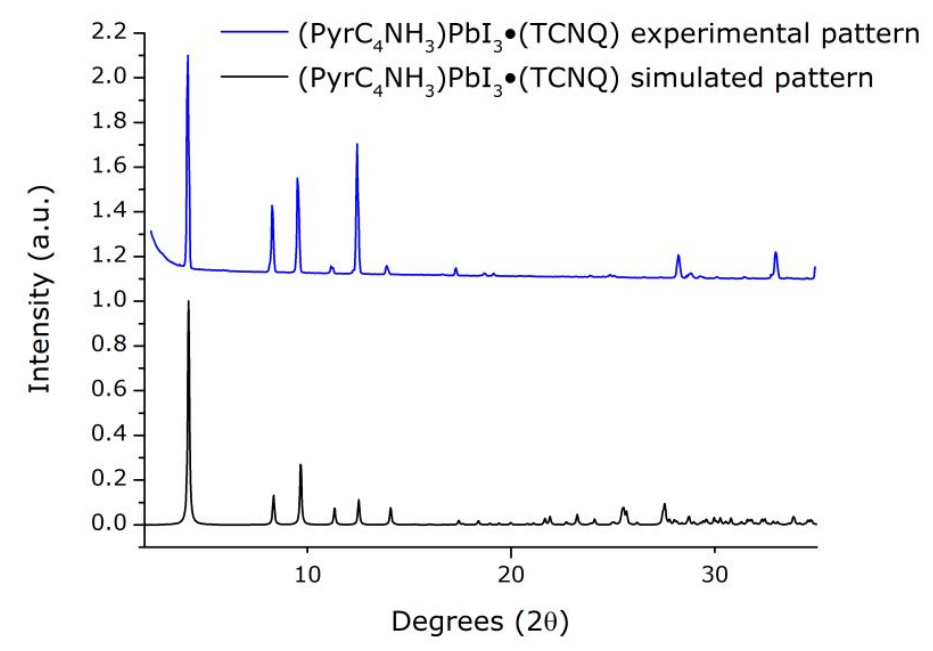

Figure S1. Powder XRD pattern of the sample of grown crystals of the 1D hybrid $\left(\mathrm{PyrC}_{4} \mathrm{NH}_{3}\right) \mathrm{PbI}_{3} \cdot(\mathrm{TCNQ})$ (top, blue) compared to the simulated pattern based on the crystal structure of $\left(\mathrm{PyrC}_{4} \mathrm{NH}_{3}\right) \mathrm{PbI}_{3} \cdot(\mathrm{TCNQ})$ obtained from single-crystal XRD (bottom, black).

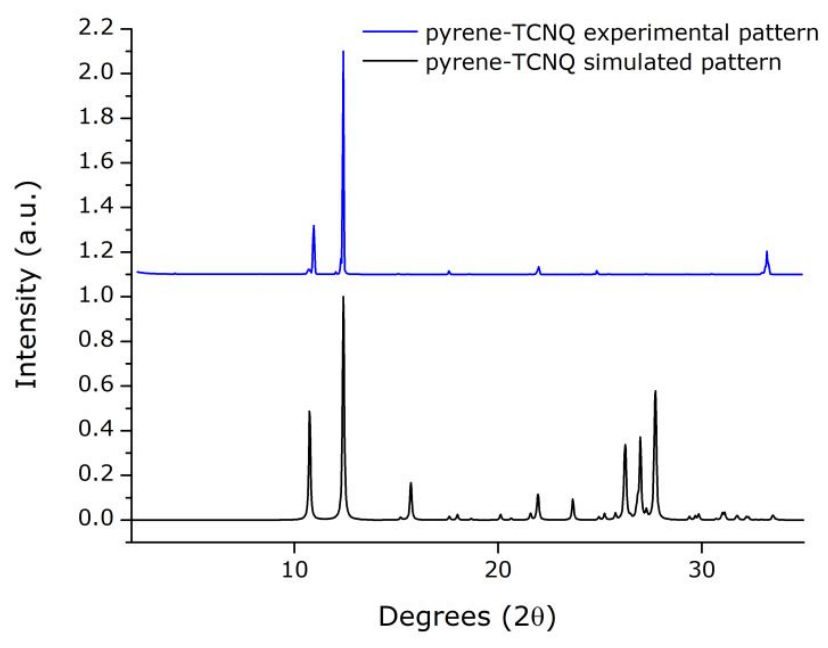

Figure S2. Powder XRD pattern of grown crystals of the organic pyrene-TCNQ charge-transfer complex (top; blue) compared to a simulated pattern based on the crystal structure of pyrene-TCNQ obtained from literature (bottom; black). ${ }^{5}$ 


\section{Comparison between 2D and 1D hybrids containing CTCs}

It must be noted that the materials described in this publication differ from the materials described in our recent communication. ${ }^{6}$ The materials that are the subject of the current publication are 1D hybrids (containing face-sharing $\mathrm{PbI}_{6}$ octahedra), while the materials described in the communication possess all the characteristics of a $2 \mathrm{D}$ layered hybrid perovskite. ${ }^{6}$ The $1 \mathrm{D}$ hybrid material has a different stoichiometry of $\left(\mathrm{PyrC}_{4} \mathrm{NH}_{3}\right) \mathrm{PbI}_{3} \bullet$ (TCNQ) compared to the $2 \mathrm{D}$ hybrid with a stoichiometry of $\left(\mathrm{PyrC}_{4} \mathrm{NH}_{3}\right)_{2} \mathrm{PbI}_{4} \cdot 2$ (TCNQ). As can be seen in Figure S4, the X-ray diffraction patterns of the two materials differ significantly, as expected.

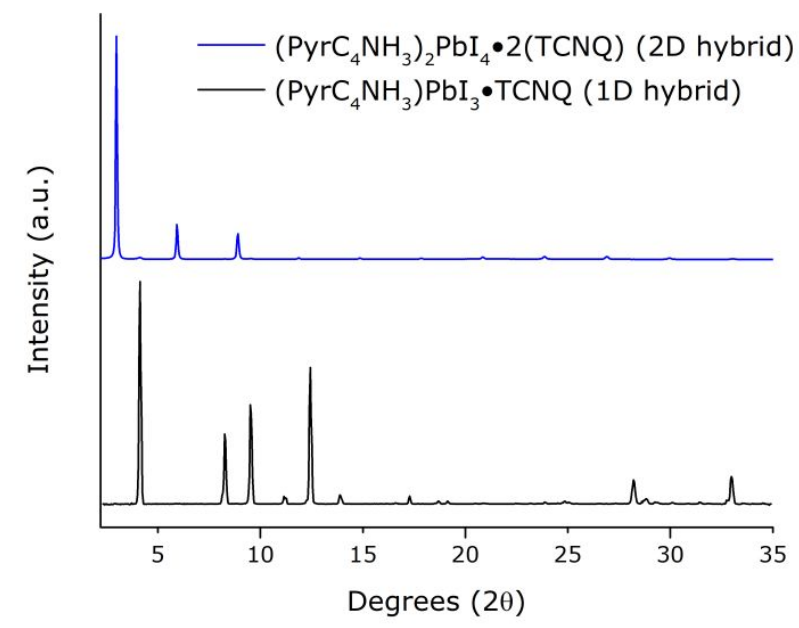

Figure S3. (Top, blue) X-ray diffraction patterns of a thin film $\left(\mathrm{PyrC}_{4} \mathrm{NH}_{3}\right)_{2} \mathrm{PbI}_{4} \cdot 2(\mathrm{TCNQ})$ and (bottom, black) of crystals of $\left(\mathrm{PyrC}_{4} \mathrm{NH}_{3}\right) \mathrm{PbI}_{3} \cdot(\mathrm{TCNQ})$. 


\section{Scanning electron microscopy}

$\mathbf{a}$

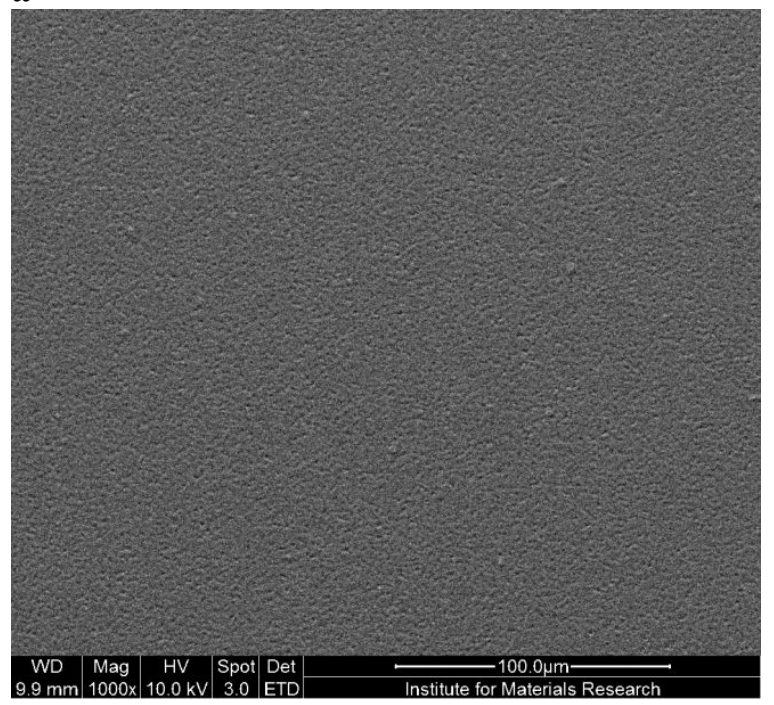

c

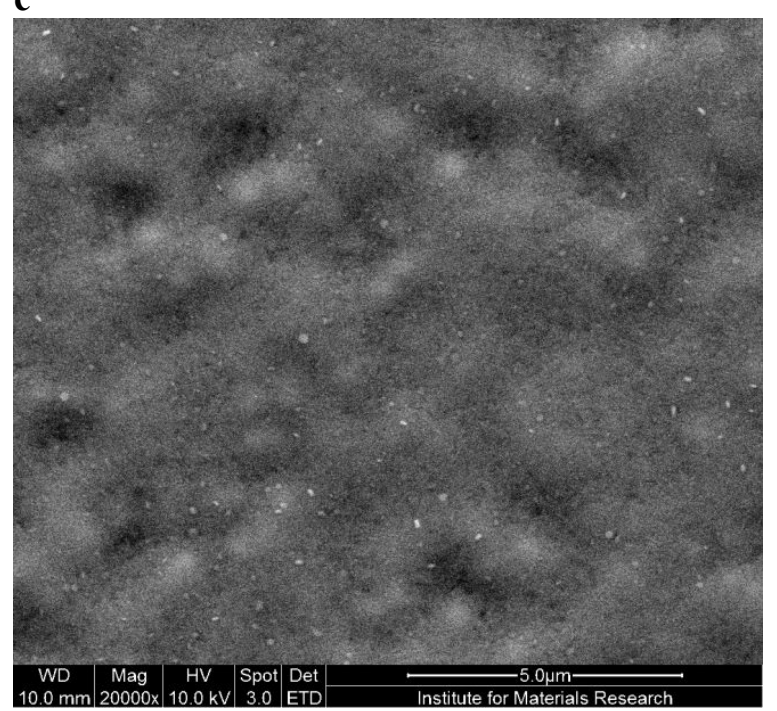

Figure S4 SEM pictures of drop-casted films of (Py b

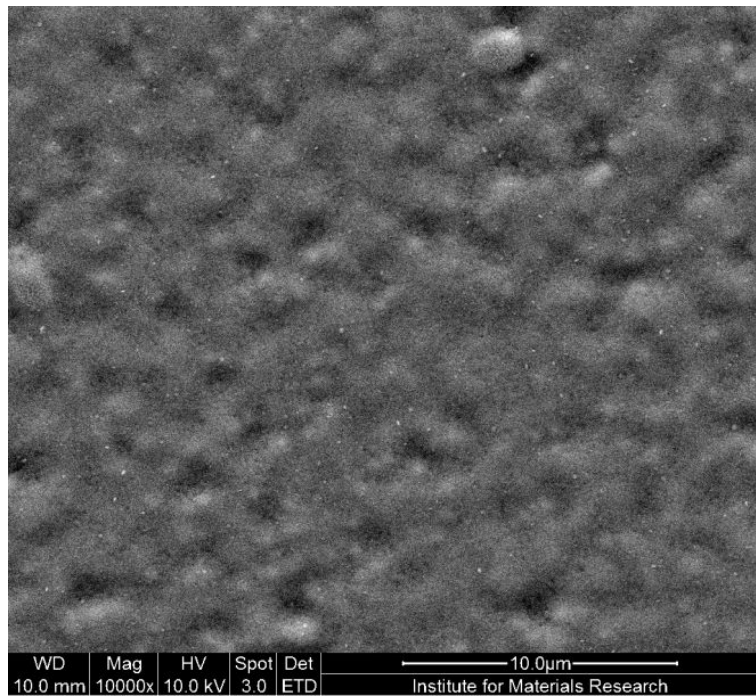

d

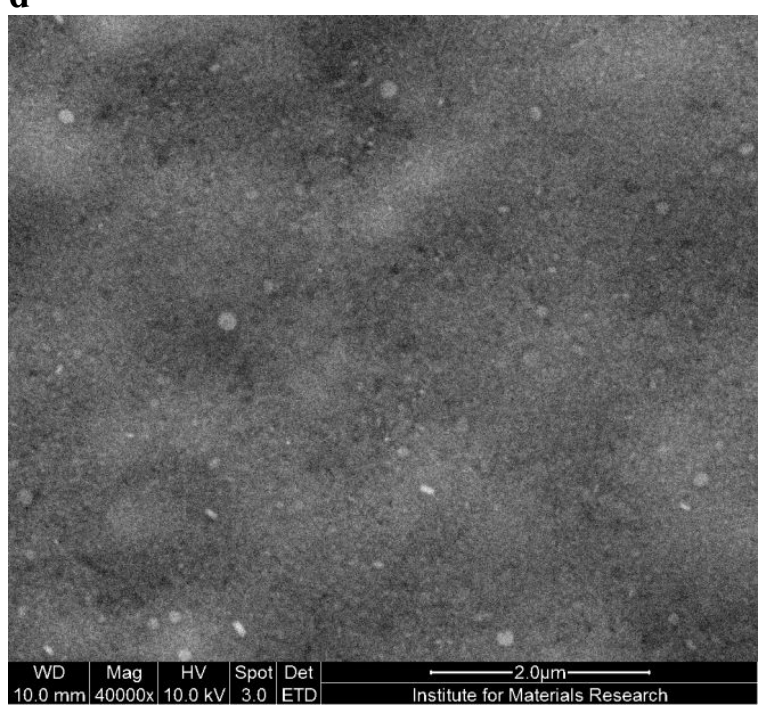

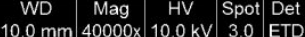

for Meterials Rese

min. 


\section{Absorption Spectra}

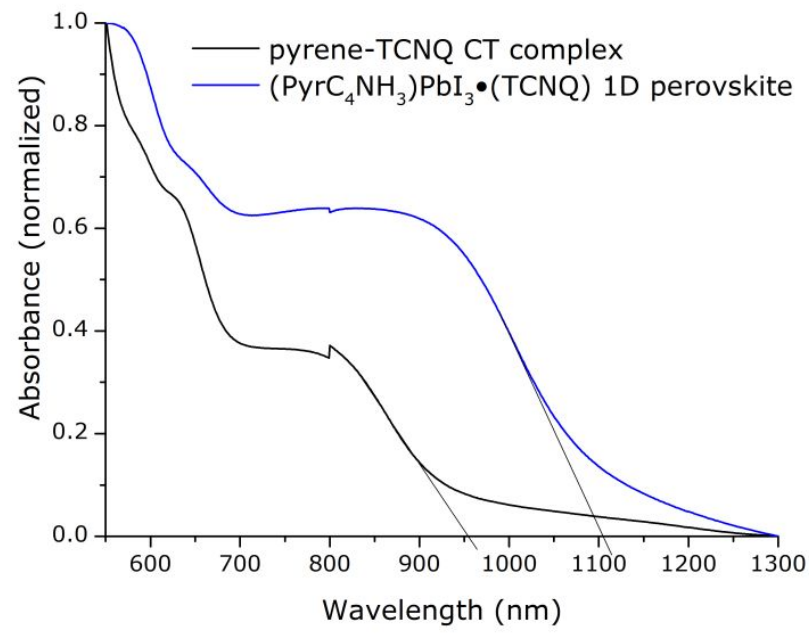

Figure S5. Absorption spectra of films of the 1D hybrid (blue) and of the charge-transfer complex pyrene-TCNQ (black). The sudden small change in absorbance at $800 \mathrm{~nm}$ is an artefact of the measurement.

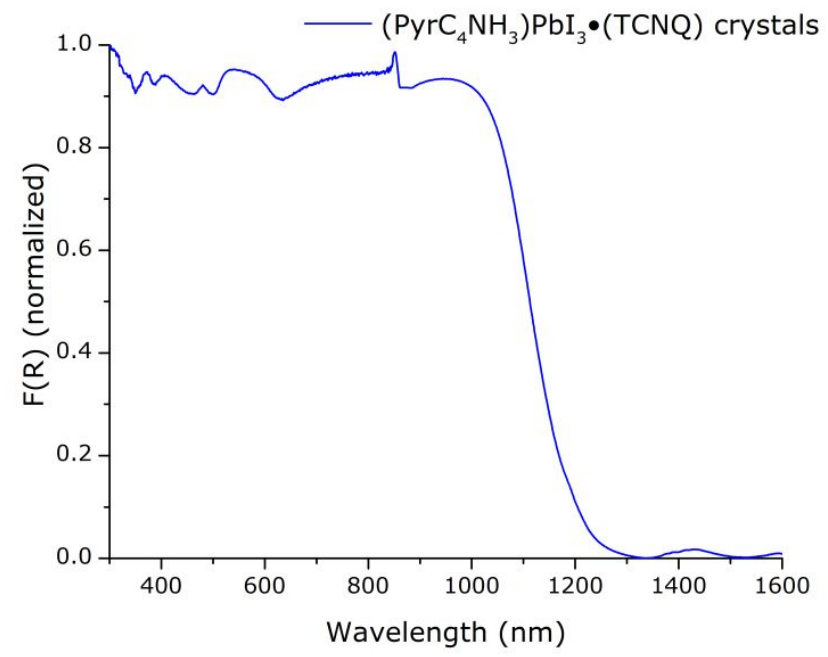

Figure S6. Absorption spectrum of $\left(\mathrm{PyrC}_{4} \mathrm{NH}_{3}\right) \mathrm{PbI}_{3} \bullet(\mathrm{TCNQ})$ measured using an integrating sphere. 


\section{Theoretical methodological study}

Table S1. Bandgap values calculated with Quantum Espresso ${ }^{7}$ with different functionals and corrections for the $1 \mathrm{D}$ hybrid $\left(\mathrm{PyrC}_{4} \mathrm{NH}_{3}\right) \mathrm{PbI}_{3} \bullet(\mathrm{TCNQ})$ crystal and the CTC pyrene-TCNQ crystal.

\begin{tabular}{|c|c|c|c|c|c|c|}
\hline \multirow{2}{*}{} & \multicolumn{3}{|c|}{ PBE } & \multicolumn{2}{c|}{ PBE0 } & HSE \\
\cline { 2 - 7 } & $\begin{array}{c}\text { k-points } \\
\text { mesh } \\
\text { without } \\
\text { SOC }\end{array}$ & $\begin{array}{c}\text { Gamma } \\
\text { without } \\
\text { SOC }\end{array}$ & $\begin{array}{c}\text { k-points } \\
\text { mesh } \\
\text { with } \\
\text { SOC }\end{array}$ & $\begin{array}{c}\text { Gamma } \\
\text { with 25\% } \\
\text { HF exch. }\end{array}$ & $\begin{array}{c}\text { Gamma } \\
\text { with 30\% } \\
\text { HF exch. }\end{array}$ & $\begin{array}{c}\text { Gamma } \\
\text { with 25\% } \\
\text { HF exch. }\end{array}$ \\
\hline$\left(\mathrm{PyrC}_{4} \mathrm{NH}_{3}\right) \mathrm{PbI}_{3} \bullet(\mathrm{TCNQ})$ & 0.36 & 0.70 & 0.34 & 1.93 & 2.18 & 1.21 \\
\hline pyrene-TCNQ & 0.69 & 0.97 & $/$ & 2.16 & 2.42 & 1.43 \\
\hline
\end{tabular}

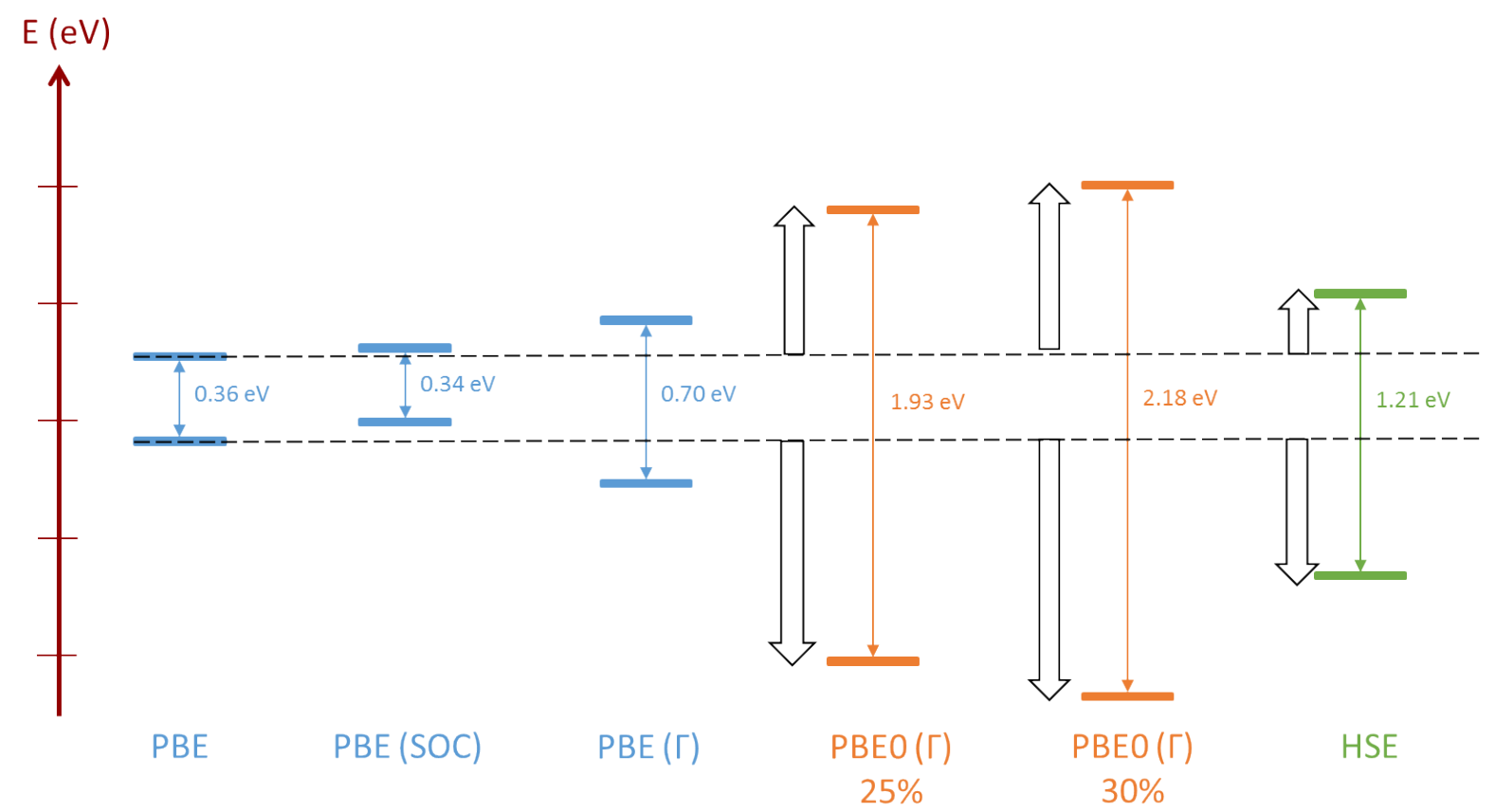

Figure S7. Dependence of the valence and conduction band edge energies of the 1D hybrid $\left(\mathrm{PyrC}_{4} \mathrm{NH}_{3}\right) \mathrm{PbI}_{3} \bullet$ (TCNQ) crystal with the DFT functional and the inclusion of Spin-Orbit Coupling (SOC) corrections.

This figure shows that implementing spin-orbit coupling effects correction is not crucial for a quantitative study of the electronic and charge transport properties of this material. However, an accurate treatment of electronic exchange and correlation (PBE0 hybrid functional) is important. 


\section{Bader analysis}

Table S2. Bader charges calculated with Quantum Espresso ${ }^{7}$ with PBE0 functional on both investigated systems: $1 \mathrm{D}$ hybrid $\left(\mathrm{PyrC}_{4} \mathrm{NH}_{3}\right) \mathrm{PbI}_{3} \cdot(\mathrm{TCNQ})$ crystal and the CTC pyrene-TCNQ crystal.

\begin{tabular}{|c|c|c|c|c|}
\hline & $\begin{array}{c}\text { Number of } \\
\text { chemical units }\end{array}$ & $\begin{array}{l}\text { Different } \\
\text { species }\end{array}$ & Ionic charge & Bader charge \\
\hline \multirow{3}{*}{$\begin{array}{c}1 \mathrm{D} \\
\left(\mathrm{PyrC}_{4} \mathrm{NH}_{3}\right) \mathrm{PbI}_{3} \bullet(\mathrm{TCNQ})\end{array}$} & \multirow[t]{3}{*}{$4 \mathrm{x}\left[\mathrm{ABPbI}_{3}\right]$} & TCNQ [B] & 0 & $-0.21(\mathrm{x} 4)$ \\
\hline & & $\begin{array}{c}\text { Perovskite } \\
{\left[\mathrm{PbI}_{3}\right]}\end{array}$ & $-1(x 4)$ & $-0.79(\mathrm{x} 4)$ \\
\hline & & Pyrene [A] & $+1(x 4)$ & $+1(x 4)$ \\
\hline \multirow{2}{*}{$\begin{array}{c}\text { CTC } \\
\text { pyrene-TCNQ }\end{array}$} & \multirow[t]{2}{*}{$2 \mathrm{x}[\mathrm{AB}]$} & TCNQ [B] & 0 & $-0.15(\mathrm{x} 2)$ \\
\hline & & Pyrene[A] & 0 & $+0.15(\mathrm{x} 2)$ \\
\hline
\end{tabular}

This table show the results of the Bader analysis performed on the two investigated systems: 1D hybrid $\left(\mathrm{PyrC}_{4} \mathrm{NH}_{3}\right) \mathrm{PbI}_{3} \bullet$ (TCNQ) crystal and the CTC pyrene-TCNQ crystal. We compare the ionic theoretical charges and the Bader charges to qualitatively assess the magnitude of the charge transfer density in the CTC.

\section{Partial Density of States (DOS)}
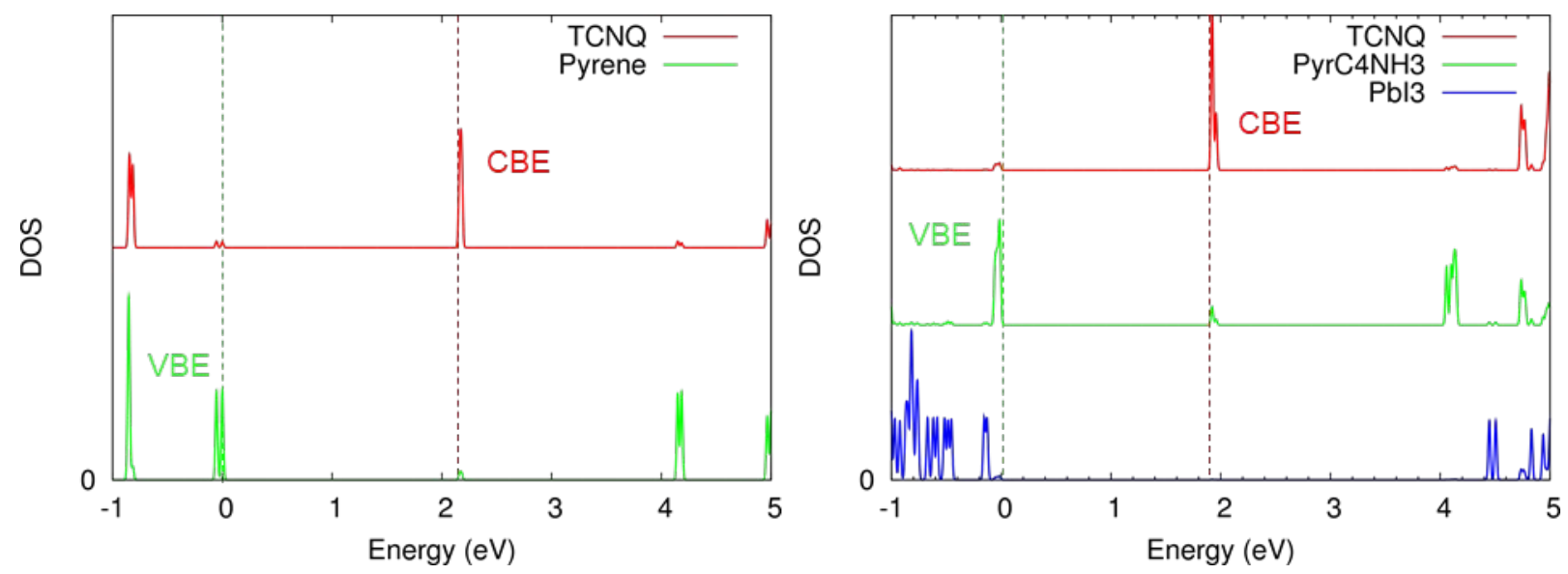

Figure S8. Comparison between the partial density of states (DOS) of the organic charge transfer complex (on the left) and the $1 \mathrm{D}$ hybrid $\left(\mathrm{PyrC}_{4} \mathrm{NH}_{3}\right) \mathrm{PbI}_{3} \bullet(\mathrm{TCNQ})$ perovskitoids crystal (on the right). Calculation performed at the same level of theory (PBE0 hybrid functional).

This figure represents the partial density of states of our two materials, with the separated contributions of the organic molecules, TCNQ and Pyrene (Pyrene+C4H8NH3 in the case of the 1D hybrid 
perovskitoids) and the inorganic part, composed of $\mathrm{Pb}$ and I octahedra. It shows that, in both cases, the valence band edge is related to HOMO of Pyrene and the conduction band edge to the LUMO of TCNQ.

\section{Pulse-Radiolysis TRMC}

From these measurements we observe that the change of conductivity as a function of time for the free charge carriers in both the 1D hybrid and organic CTC salt is not largely affected by temperature (Figure S8). This suggests that the mobility and recombination are not largely affected by acoustic lattice vibration and/or activated charge transport by hoping in the organic compounds.

In fact, in Figure S9 it is clear that the normalized recombination of charge carriers for 1D hybrid and the organic CTC salt have the same decay dynamics. Confirming that the mobility of charge carriers in both materials is similar and the transport is limited by the coupling of the organic compounds.
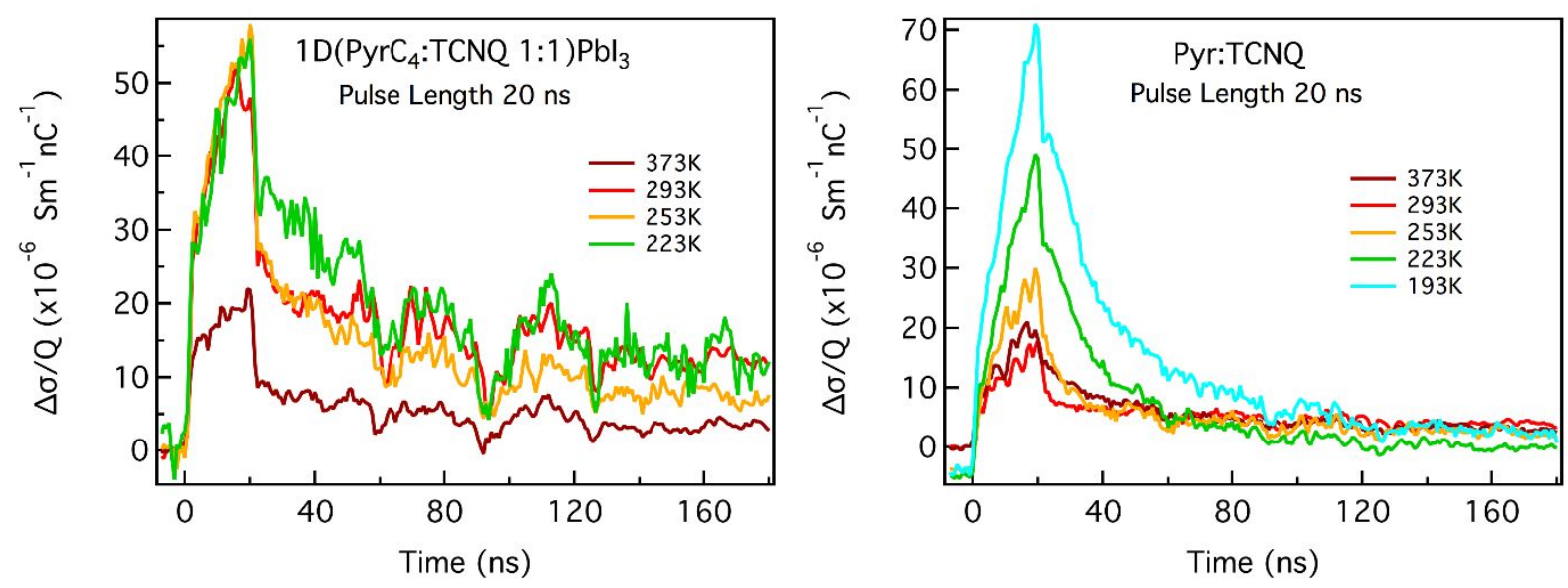

Figure S9. Conductivity transients as a function of temperature.

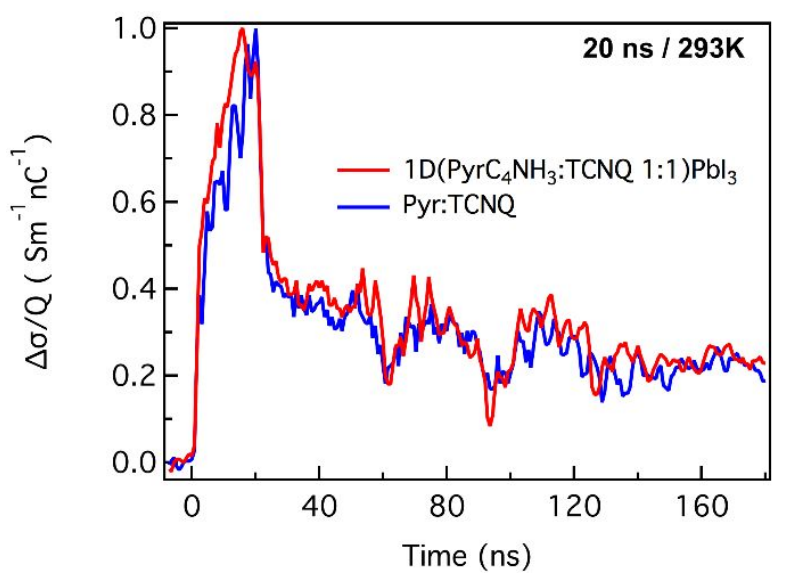

Figure S10. Normalized Conductivity transients at $293 \mathrm{~K}$. 


\section{Photoconductivity TRMC}

We performed an intensity dependent study (see Figures 11 and 12) for both the 1D compound and the organic salt at the excitonic peaks (500 nm and $489 \mathrm{~nm}$, respectively) and the charge transfer state (600 $\mathrm{nm}$ ). The fluence intensities required in order to obtain conductivity signals from these compounds were in the order of $1.73 \times 10^{14}$ photons $/ \mathrm{cm}^{2}$ to $5.36 \times 10^{15}$ photons $/ \mathrm{cm}^{2}$ (which results in concentrations of $2 \times 10^{18} 1 / \mathrm{cm}^{3}$ to $8.6 \times 10^{19} 1 / \mathrm{cm}^{3}$, depending on the thickness of the film). These concentrations are rather high and evidence the high binding energy of the 1D compound.

As described in the experimental methods, laser induced TRMC measurements are sensitive to the exciton binding energy $\left(\mathrm{E}_{\mathrm{b}}\right)$ of the materials. The charge carriers generated by the laser are very close to each other and if the $E_{b}$ is too high they will recombine during the pulse. Ultimately, the photoconductivity data obtained is the product of the mobility and the yield of free charge carriers. From the results, the high fluences required and low photo conductivities obtained for these materials (order of $1 \times 10^{-3} \mathrm{~cm}^{2} / \mathrm{Vs}$ ) reflect that the yield of dissociation must be very low due to their high $\mathrm{E}_{\mathrm{b}}$. This is not surprising as the $E_{b}$ of pure organic materials and low dimensional hybrid perovskites is known to be very high $\sim 380 \mathrm{meV}$ for $2 \mathrm{D}$ hybrid perovskites and it should be even higher for materials with a lower dimensionality (1D) as the one studied in this work.

The main conclusion revealed by our study is that the 1D hybrid compound has an improved charge separation or higher yield of free charge carriers than the organic charge transfer salt. This is shown by the one order of magnitude larger photoconductivity obtained for 1D hybrid perovskitoids at all fluences and the long-lived tale that reflects the separation of charge carriers and photoconductivity of holes in the inorganic $\mathrm{PbI}$ octahedra. For the organic salt, the photoconductivity signal is very small and decays faster due to exciton recombination. In addition, we are sure that the 1D hybrid perovskitoids has a higher yield of free charge carries because it was determined by PR-TRMC measurements (that probes the mobility of free carriers only) that the mobility of charge carriers in these materials is very similar (see Figure 4 in manuscript).

Regarding the recombination dynamics, we observe that for both compounds the photoconductivity decreases as the photon intensity increases. This shows that during the pulse if more charge carriers are generated they recombine faster. Now, if the maximum photoconductivity signal is normalized (Figures 1 and 2 Right panel) we observe that the decay rate is the same independently of the fluence (initial concentration of carriers). This proves that the decay kinetics in these materials follow a $1^{\text {st }}$ order process. For the 1D hybrid perovskitoids this shows that the free holes in the inorganic octahedra move around this layer and recombine at the same rate independently of the fluence with the electrons on the organic complex. 

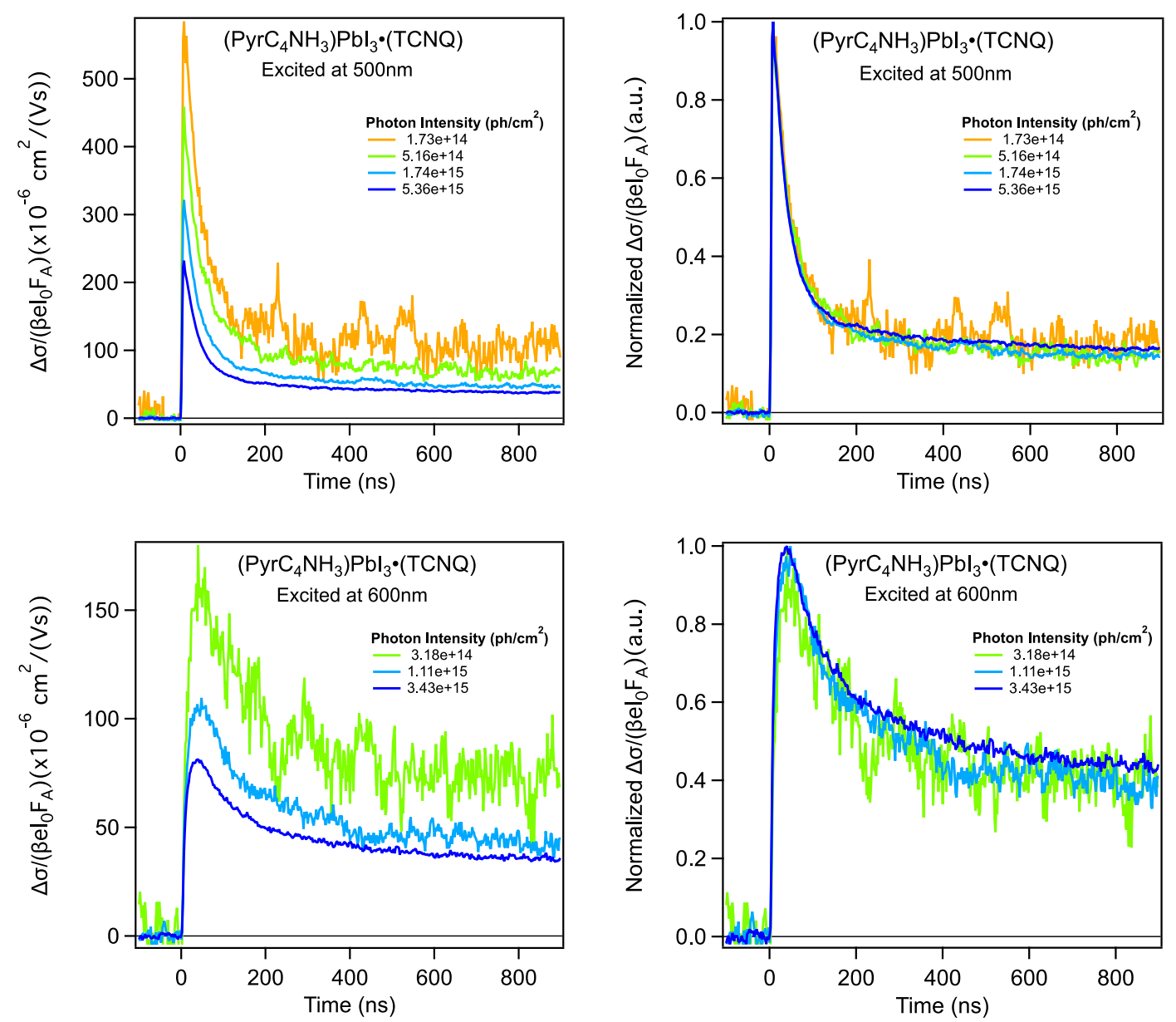

Figure S11 TRMC photon intensity dependence for $1 \mathrm{D}\left(\mathrm{PyrC}_{4} \mathrm{NH}_{3}\right) \mathrm{PbI}_{3} \bullet(\mathrm{TCNQ})$ at $500 \mathrm{~nm}$, excitonic peak, (top) and $600 \mathrm{~nm}$, charge transfer state, (bottom). 

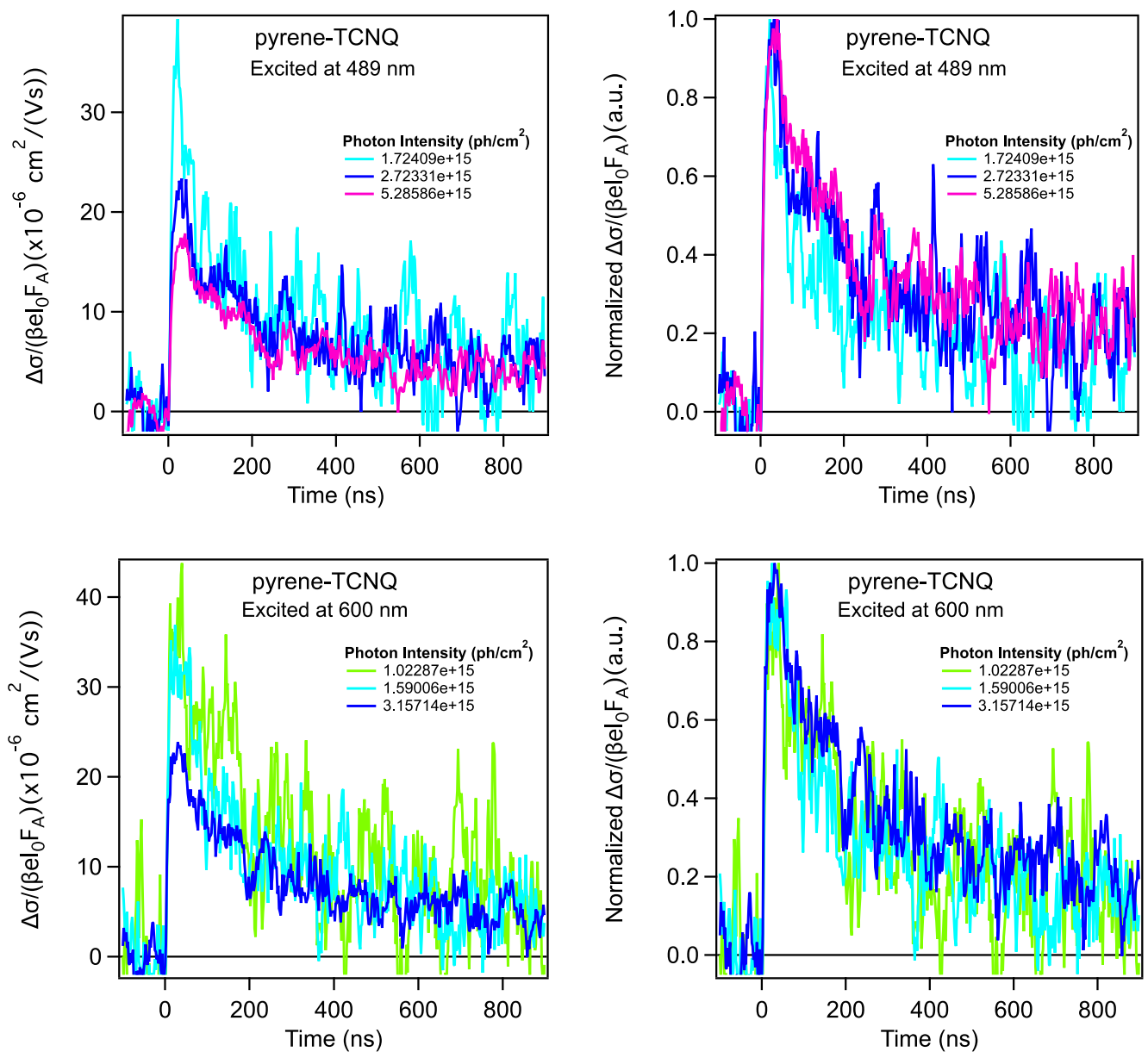

Figure S12 TRMC photon intensity dependence for (Pyrene-TCNQ) at $489 \mathrm{~nm}$, excitonic peak, (top) and $600 \mathrm{~nm}$, charge transfer state, (bottom). 


\section{Thermal stability of the hybrid}

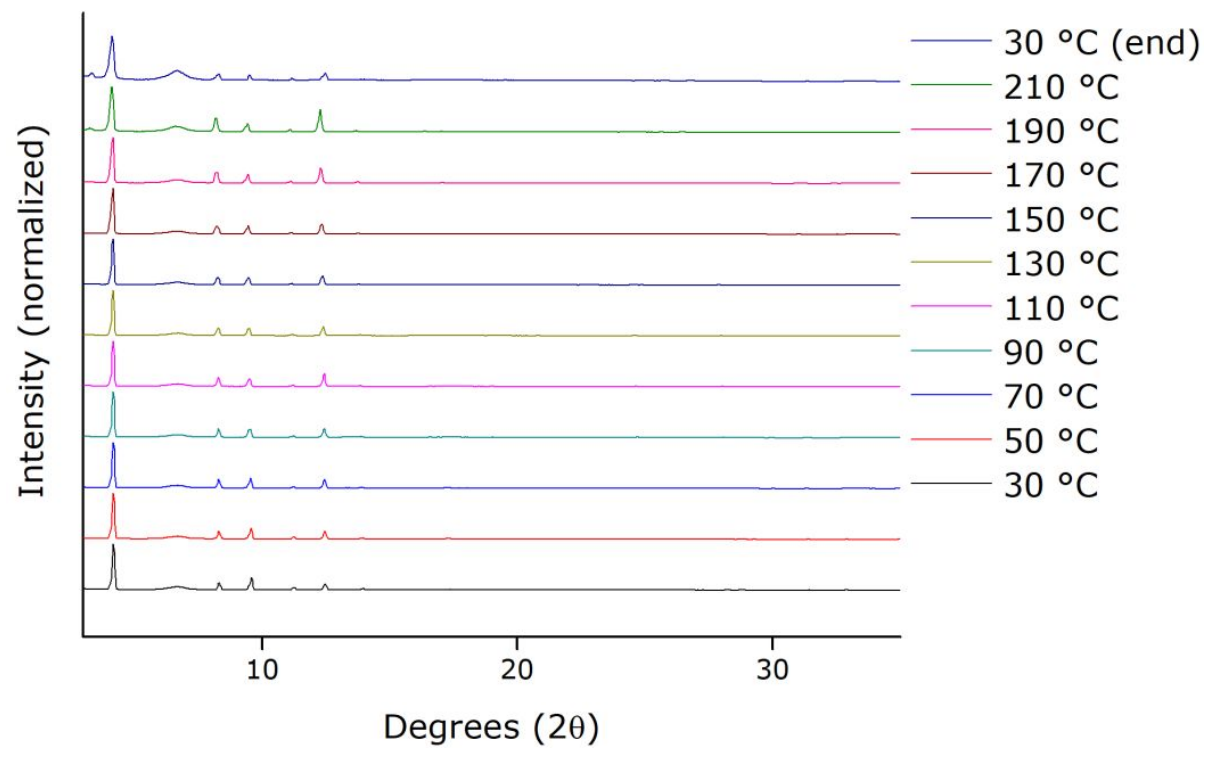

Figure S13. Temperature-controlled XRD patterns of crystals of $\left(\mathrm{PyrC}_{4} \mathrm{NH}_{3}\right) \mathrm{PbI}_{3} \cdot(\mathrm{TCNQ})$ in ambient atmosphere. The appearance of a new phase is apparent at $210^{\circ} \mathrm{C}$ (with a main reflection at $\sim 3.3^{\circ}$ 29). The top pattern was obtained after cooling down the sample to room temperature after the heating ramp.

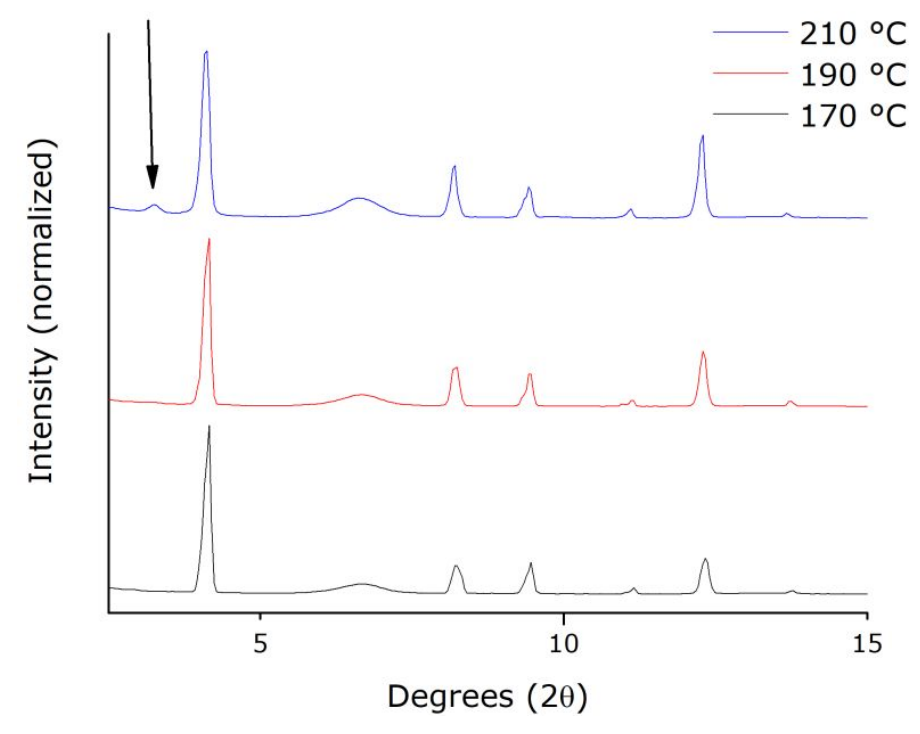

Figure S14. Temperature-controlled XRD patterns of crystals of $\left(\mathrm{PyrC}_{4} \mathrm{NH}_{3}\right) \mathrm{PbI}_{3} \bullet(\mathrm{TCNQ})$ in ambient atmosphere between $170{ }^{\circ} \mathrm{C}$ and $210^{\circ} \mathrm{C}$ (focusing on the degradation). The broad peak at $\sim 6.7^{\circ} 29$ is due to Kapton tape present in the high-temperature XRD chamber. 


\section{REFERENCES}

(1) Rigaku Oxford Diffraction 2015. CrysAlis Pro; Rigaku Oxford Diffraction, Yarnton, England.

(2) O.V. Dolomanov, L.J. Bourhis, R.J. Gildea, J.A.K. Howard, H. Puschmann, J. Appl. Crystallogr. 42 2009, 339-341.

(3) G.M. Sheldrick, Acta Crystallogr. Sect. A64 2008, 112-122.

(4) G.M. Sheldrick, Acta Crystallogr. Sect. C71 2015, 3-8.

(5) Dobrowolski, M. A.; Garbarino, G.; Mezouar, M.; Ciesielski, A.; Cyranśki, M. K. Structural Diversities of Charge Transfer Organic Complexes. Focus on Benzenoid hydrocarbons and 7,7,8,8Tetracyanoquinodimethane. CrystEngComm 2014, 16 (3), 415-429.

(6) Van Gompel, W. T. M.; Herckens, R.; Van Hecke, K.; Ruttens, B.; D'Haen, J.; Lutsen, L.; Vanderzande, D., Towards 2D layered hybrid perovskites with enhanced functionality: introducing charge-transfer complexes via self-assembly. Chem Commun (Camb) 2019, 55, (17), 2481-2484.

(7) Giannozzi, P., et al., Quantum Espresso: a modular and open-source software project for quantum simulations of materials, Journal of Physics: Condensed Matter 2009, 21, 395502. 